\title{
SUBSTITUIÇÃO E PADRONIZAÇÃO DO EQUIPAMENTO DE MOVIMENTAÇÃO DE VÍTIMAS EM SALVAMENTO (EMVS) TIPO CESTO: PROPOSTA METODOLÓGICA E ESTUDO DE CASO
}

\author{
Wellington Adriano Cruz ${ }^{1}$ \\ Alexandre Sergio de Oliveira Angelin ${ }^{2}$
}

\section{RESUMO}

Ao tomar como base observações relatadas por profissionais Bombeiros sobre possíveis falhas com o Equipamento de Movimentação de Vítimas em Salvamento (EMVS) tipo cesto, optou-se em realizar um estudo detalhado no intuito de obter o equipamento ideal para o resgate de vítimas em ocorrências de Bombeiros. Por meio do método institucional de Objeto de Aprendizagem Colaborativa (OAC) foi possível ilustrar que o ato da melhoria de todos quanto a segurança, está na condição de um novo equipamento operacional. As considerações sugerem a substituição do EMVS tipo cesto convencional por um tipo cesto de aço inox ou titânio, bem como a padronização da amarração da cabeceira no içamento por meio de POP. Conclui-se, portanto, que o uso do EMVS tipo cesto inox e a padronização na corporação, são ações que reduzem riscos às vítimas, aos profissionais que laboram na atividade de salvamento, bem como na solução de problemas institucionais neste âmbito.

Palavras Chave: EMVS tipo cesto; Procedimento Operacional; Ancoragem cabeceira.

\footnotetext{
${ }^{1}$ Profissional do Corpo de Bombeiros do Estado de São Paulo. Especialista em Engenharia de Segurança Contra Incêndio e Pânico pela PUC.Docente em diversos cursos de Bombeiros no país e instrutor do Departamento de Salvamento Terrestre da Escola Superior de Bombeiros de São Paulo. E-mail: bombertom@gmail.com.

${ }^{2}$ Profissional do Corpo de Bombeiros do Estado de São Paulo. Mestre pela Universidade de São Paulo na área de Engenharia III, Docente em diversos cursos de Bombeiros no país. Instrutor do Departamento de Salvamento Aquático da Escola Superior de Bombeiros (ESB) de São Paulo. Email:alexandreangelin@usp.br / alexandreangelin@yahoo.com.br
} 


\title{
RESCUE HANDLING EQUIPMENT (EMVS) BASKET TYPE: METHODOLOGICAL PROPOSAL AND CASE STUDY
}

\begin{abstract}
Based on observations reported by firefighters professionals about possible failures with Rescue Victims Handling Equipment (RVHE) basket stretch, were decided to carry out a detailed study in order to obtain the ideal equipment for rescue of victims in occurrences.Through the institutional Collaborative Learning Object (CLO) method, were possible to illustrateth at the actofim provingevery one in terms of safety is in conditionof a new operational equipment. The considerations suggest that there placement of the conventional (RVHE) basket stretch by a stain less steel or titanium type, as well as the standard ization of the head board mooring in the liftby means of POP. Concluded, there fore, that the use of stain less steel (RVHE) baskets tretch and the standardization in the corporation are actions tha treducerisks to victims, to professional swho work in rescue activity, as well as in the solution of institutional problems in this area.
\end{abstract}

Keywords: RVHE Basket stretch; Operational Routine; Head board anchorage.

Artigo Recebido em 12/07/2021 e Aceito em 28/12/2021 


\section{INTRODUÇÃO}

As macas cestos, comumente denominadas de rescue basket (LAWRENCE, 1964) foram referenciadas como excelentes equipamentos para o resgate de vítimas em local de difícil acesso.

Muitas das macas foram adequadas para a realidade com o formato de trabalho (CROME, 1939), porém a partir dos estudos de Ernest Lawrence, os equipamentos ganharam novas evoluções e o produto tornou-se cada vez mais leve, simples e direcionada para o tipo de atividade (VARGHESE, 2003).

A aplicação da maca de resgate depende da necessidade por parte da equipe na cena de ocorrência. Para as equipes de socorro, o uso desse equipamento é de extrema importância para a obtenção da eficiência no atendimento às vítimas, em que pese o fator segurança, conforto e qualidade no atendimento da vítima (IWANO; OSUKA e AMANO, 2011).

As equipes especializadas em resgate e assessoria médica, como os Wilderness Medicine (DA SILVA, 2012) e equipes de salvamento, como os Corpos de Bombeiros da Polícia Militar do Estado de São Paulo (CBPMESP), utilizam as macas em suas atividades. Atualmente, a nomenclatura utilizada para as macas de resgate é Equipamento de Movimentação de Vítima em Salvamento (EMVS).

Apesar de existir diversos modelos de EMVS para finalidades distintas (LAWRENCE, 1964; VARGHESE, 2003), no resgate emergencial há dois tipos essenciais que suprem a finalidade de salvamento médico em ambientes inadequados e/ou condições naturais agressivas ( $\mathrm{CHO}$, et al., 2018) - a tipo envelope e a tipo cesto.

Devido ao crescente aumento da procura para aquisição por parte das equipes de emergência nestes tipos de equipamentos e ao reflexo de inúmeras causalidades já ocorridas com estes equipamentos (IWANO; OSUKA e AMANO, 2004), em que pese ainda um contexto real, de uma ocorrência 
destaque do CBPMESP, na qual um EMVS tipo cesto veio a se romper da corda por onde estava ancorado, uma recomendação de estudo foi lançada.

Assim, sugeriu-se a proposta de analisar qual teria sido o motivo do rompimento da corda? Qual seria o modelo de equipamento ideal para os serviços de salvamento? E qual o tipo de ancoragem padrão para o içamento de EMVS tipo cesto em ambientes variados e nas atuações diversificadas?

$\mathrm{Na}$ condição de compreender todo um processo prático operacional dos serviços de Bombeiros, um estudo foi desenvolvido na Escola Superior de Bombeiros (ESB) pelo método da análise do Objeto de Aprendizagem Colaborativa (OAC). O método é dividido em fases e procura: 1) identificar a inconsistência operacional; 2) eliminar o problema de forma a trazer uma solução viável consensual e; 3) atuar de forma gradativa para a substituição de um objeto inconsistente.

\section{PROPOSTA METODOLÓGICA}

O trabalho retrata um estudo pelo método do Objeto de Aprendizagem Colaborativa (OAC). O OAC é um termo oriundo da área educacional e sintetiza a aprendizagem por meio da interação mútua (SANTOS SOUZA, 2005), a partir da manifestação acadêmica da área de ensino, com as considerações práticas observadas no dia a dia.

O modelo OAC foi adaptado para os serviços de Bombeiros. Na ocasião, procurou-se proporcionar resultados viáveis quanto à observação de inconsistências operacionais, ao pressupor a vivência dos serviços de Bombeiros, por meio da aprendizagem e da colaboração, como ocorre em ensinamentos à distância (OKADA, 2003).

O método OAC está inserido em três grandes momentos e voltado ao objeto de estudo. Visa: (a) observar uma inconsistência; (b) aplicar uma solução viável; e (c) sugerir mudança por uma nova metodização. É constituído 
em 3 fases distintas. A Fase I, da Observação de uma Inconsistência que é dividida em 2 etapas, sendo a Etapa 1, da Elaboração de um Time de Aprendizagem (TA), composto de até 5 profissionais conhecedores do objeto; e a Etapa 2, da Observação do Objeto, em que pese reconhecer considerações de um cenário operacional. A Fase II, denominada de Objetivo Operacional, é constituída pela Etapa 3 e procura trazer uma expectativa de melhoria do objeto a partir do que foi analisado. E, por fim, a Fase III, da Comprovação Prática, que é composta por 2 etapas, sendo a Etapa 1 deEstudo para Investimento e Implementação e a Etapa 2 da Aplicação Prática em si. A Figura 1 ilustra as fases e etapas do método do trabalho.

Todo o estudo foi desenvolvido na Escola Superior de Bombeiros (ESB) e contou com a colaboração dos Departamentos da Escola, por meio de profissionais da área do estudo.

Figura 1 - Fases do Objeto de Aprendizagem Colaborativa.

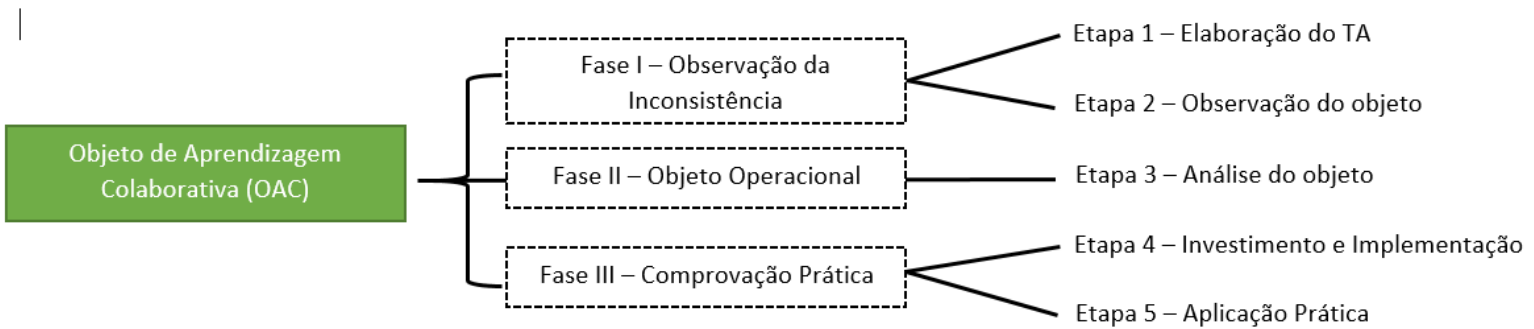

Fonte: Elaborado pelo autor.

\subsection{Estudo de Caso - Estação Almanara}

O trabalho traz um estudo real da Estação de Bombeiros Militares Almanara, localizada no município de São Paulo/SP e vivenciada no dia 23 de janeiro do ano de 2020. O fato ocorreu durante o transporte de uma vítima de um local elevado até o solo, com o uso do EMVS tipo cesto.A vítima foi colocada dentro do EMVS e retirada pela janela através de um sistema de tirolesa. O equipamento foi ancorado pela cabeceira em uma corda guia e em 
um descensor. Ao iniciar o processo da debreagem - processo que ocorre a movimentação do equipamento até o solo; a corda que estava presa na parte plástica do equipamento veio a se romper ocasionando a descida da vítima subitamente ao solo. Apesar da altura considerável, o quadro da vítima não se agravou uma vez que estava presa a uma segunda corda da tirolesa. A Figura 2 ilustra os três momentos distintos desta ocorrência, sendo o momento da descida da vítima, o do tipo de amarração utilizada e a do resultado final do equipamento após o rompimento.

Figura 2 - llustração sequencial do processo de ruptura do EMVS.

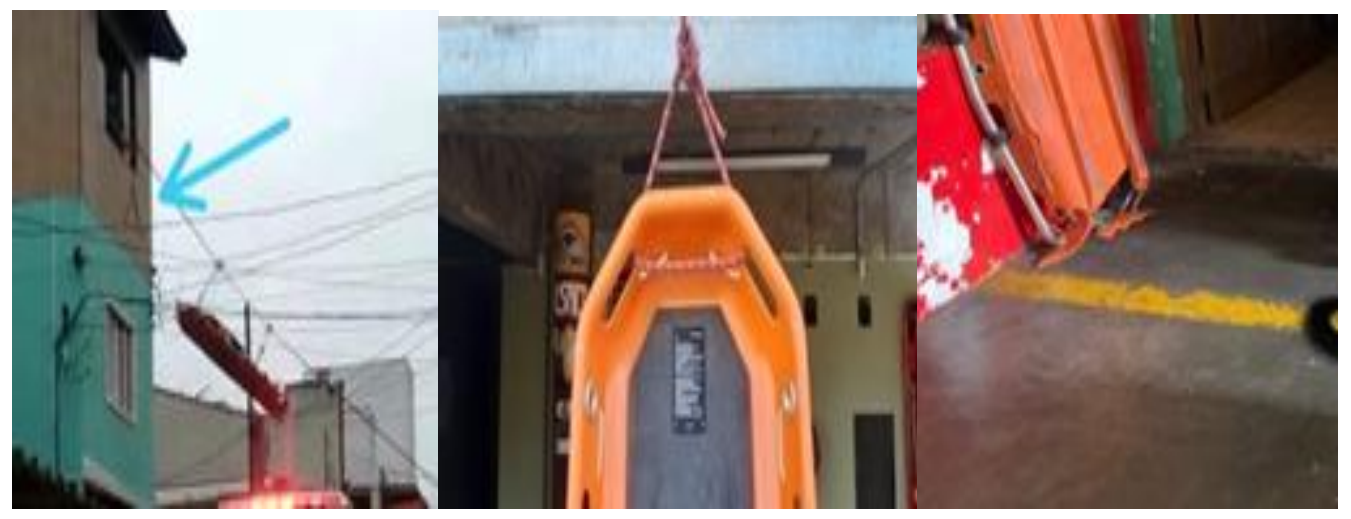

Fonte: Próprio autor.

Ao analisar as fotografias da Figura, observa-se que na foto inicial, a equipe fez a amarração de tração na parte plástica da cabeceira, o que ocasionou a quebra da estrutura. Constata-se, orientado pela seta azul, a ruptura do plástico do EMVS tipo cesto, com o instante da descida da maca. $\mathrm{Na}$ foto do meio, há o processo da amarração e, na última,a foto do danono equipamento, o que fez com que se torna-se irreversível para o trabalho. 


\section{APLICAÇÃO PRÁTICA DO MÉTODO OAC}

\subsection{Fase 1: Observação de uma Inconsistência}

Nesta fase primária ocorre o engajamento do time com o objeto a ser analisado. Consiste em estudar o EMVS tipo cesto e analisá-lo pelo TA. O TA foi composto por 3 profissionais docentes da ESB. O estudo enfatizou o uso do EMVS tipo cesto como objeto de estudo, pois supõem-se que houve uma falha no equipamento. Propôs-se ainda explorá-lo, dentro de cenários de salvamento, e investigá-lo,a partir das inconsistências durante o seu uso, como referenciada no estudo de caso.

Portanto, foram discutidos pelo TA conhecimentos sobre EMVS tipo cesto, composição do material, descrição sobre termoplásticos, armazenamento operacional, desvantagens do equipamento e procedimentos operacionais aplicados.

\subsubsection{Revisão conceitual}

O nome original do EMVS tipo cesto foi denominado como basketstretchers (LAWRENCE, 1964). Estes equipamentos são utilizados em áreas de parques, estádios e eventos, além de ser muito aplicado também na área médica (SHELL e SHELL, 2016).

A estrutura de um EMVS tipo cesto é constituída de uma estrutura de alumínio fechada e revestida por um corpo plástico. A camada plástica que reveste o equipamento, tecnicamente, é composta por Polietileno de Alta Densidade (PEAD) e/ou Policloreto de Vinila (PVC) (SPENCER, 2016).

Nela, há espaços laterais que servem para o escoamento d'água e espaços fechados para proteção a possíveis impactos. E, para o içamento, há dispositivos laterais, reforçados por anéis de fixação, com bordas de aço que comumente são denominados de ilhoes (SPENCER, 2016). 
Quanto ao uso de plástico no EMVS tipo cesto, ele é utilizado devido a visão estratégica que esse tipo de material tem no mundo, como no âmbito da preservação e da conservação do meio ambiente devido ao processo de reciclagem (CARASCHI e LEÃO, 2002). Quanto a preservação, ao reciclar plástico durante o processo de fabricação, qualquer material plástico reciclável poderia ser reaplicado em um processo produtivo. E na conservação, 0 processo de reciclagem torna a coleta dos materiais um ato repetido e cotidiano no mundo, pois a razão é o seu rápido descarte ao longo do tempo.

No entanto, há problemas com os termoplásticos ao ser aplicado no EMVS tipo cesto. Na fabricação de peças plásticas, normalmente, não se exigem especificações técnicas, basta ter aplicabilidades específicas. Porém para equipamentos de segurança, não é qualquer material plástico que pode ser reciclável ou reaplicado em um processo produtivo. No processo de injeção dos termoplásticos há parâmetros que influenciam nas características e nas propriedades mecânicas do material (COLTRO, GASPARINO e QUEIROZ, 2008). Ao aplicar diversos tipos de materiais, a mistura corrobora para a perda das propriedades termo-elástica e de resistência, como também impacta na perda das propriedades específicas do plástico.O resultado é tornar-se inservível para a aplicação de salvar vidas, pois aumenta os efeitos nocivos no plástico (NOVELINI, 2018)

Quanto às desvantagens do material, a principal é a rápida degradação natural ao observar que este tipo de degradação ocorre pela exposição do equipamento. Por observar que os EMVS tipo cesto, nos serviços de Bombeiros do Estado de São Paulo, fica armazenado em cima dos caminhões e, consequentemente, exposto à luz solar, radiação ultravioleta e a intempéries, a degradação se torna constante (STRICKLAND, 2000).

Ao ficar exposto a radiação ultravioleta ${ }_{2} 0$ processo de degradação superficial natural do material plástico é acelerado, o que ocasiona 0 aparecimento de buracos e manchas escuras (BORBA, 2016). As manchas são sinais evidentes de que, naquele ponto, o material está suspeito a perda da 
deformação na ruptura e da elasticidade e aumento de tensão na força máxima. Somado a isso, há agentes que potencializam as microfissuras ocasionadas por pedras e terrenos irregulares,com a exposição a chuva, a poeira e outros materiais, como óleo e graxas.

Quanto a degradação por desgaste, na conferência americana Firehouse nos Estados Unidos, foi ressaltado que o uso excessivo e contínuo do EMVS tipo cesto, de forma prolongada e sem devidos cuidados, potencializa a diminuição do tempo de vida útil (STRICKLAND, 2000, p.23). Na ocasião, os sinais evidentes faz com que este equipamento de salvamento torna-se inutilizável, logo, sujeito ao descarte para a atual finalidade por não garantir a resistência do material.

Ao observar o manual de Spencer (2016), o EMVS tipo cesto tem uma vida útil de, aproximadamente, 10 anos, a contar da data da venda do produto. A partir deste período, o equipamento deve ser eliminado e informado ao fabricante a forma como será esse processo de descarte, a fim de evitar um possível reuso do material.

Porém, muitos destes EMVS são usados por muito mais tempo no serviço operacional e de forma incorreta. Como nos procedimentos adotados pelo CBPMESP para o içamento do EMVS tipo cesto são na posição vertical e horizontal.Para o içamento na horizontal utiliza-se os ilhoes como ancoragem e para o içamento na vertical é utilizado a amarração de cabeceira, sendo esta realizada de duas maneiras. A Figura $3 \mathrm{com}$ a fotografia da esquerda, ilustra a amarração de cabeceira do Departamento de Terrestre e a fotografia da direita, ilustra a amarração a amarração de cabeceira do Departamento de Altura. 
Revista Científica do Corpo de Bombeiros Militar de Pernambuco

Artigo Publicado no Vol.07 N.20 - Edição Especial 2021 - ISSN 2359-4829

Versão on-line disponível em: $\underline{\text { http://www.revistaflammae.com }}$

Figura 3 - Amarração de cabeceira aplicada nos Departamentos da ESB

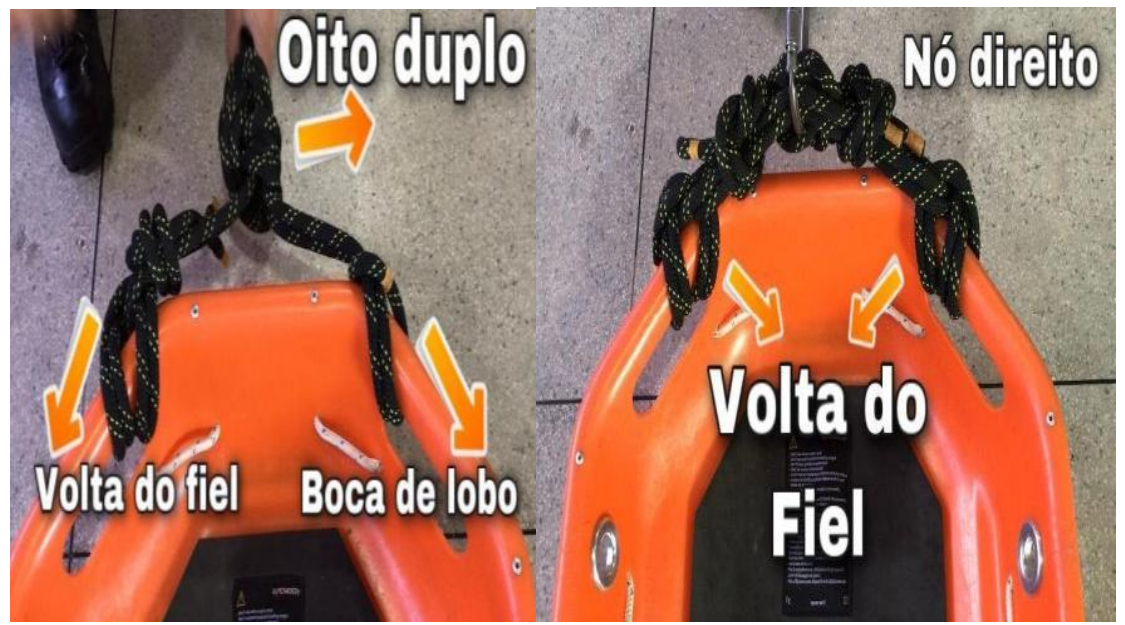

Fonte: Próprio autor.

\subsection{Fase 2 - Objetivo Operacional}

No estudo do objeto, a partir do que foi observado, o TA propôs, como objetivo operacional, soluções que possam ser atingíveis, mensuráveis e flexíveis, através das seguintes afirmativas:

1. Sugestão de adequação na forma de acondicionamento do EMVS tipo cesto nas viaturas operacionais;

2. Troca do EMVS tipo cesto por um com material de maior durabilidade e resistência; e

3. Padronização de ancoragem de cabeceira no CBPMESP.

\subsubsection{Acondicionamento do EMVS tipo cesto nas viaturas}

O armazenamento do EMVS tipo cesto em gavetas específicas nas viaturas de bombeiro pode ser algo inovador no processo de acondicionamento do equipamento, seja no Estado de São Paulo ou no Brasil. Pois, ao adquirir novas viaturas é possível elaborar no memorial descritivo, o local específico para o EMVS, sem atrapalhar o uso funcional das viaturas. A Figura 4 ilustra um caminhão projetado para o acondicionamento do EMVS Cesto em compartimento próprio, no interior da gaveta. 


\section{Revista FLAMMAE}

Revista Científica do Corpo de Bombeiros Militar de Pernambuco

Artigo Publicado no Vol.07 N.20 - Edição Especial 2021 - ISSN 2359-4829

Versão on-line disponível em: $\underline{\text { http://www.revistaflammae.com }}$

Figura 4 - Acondicionamento do EMVS tipo cesto em compartimento próprio da viatura.

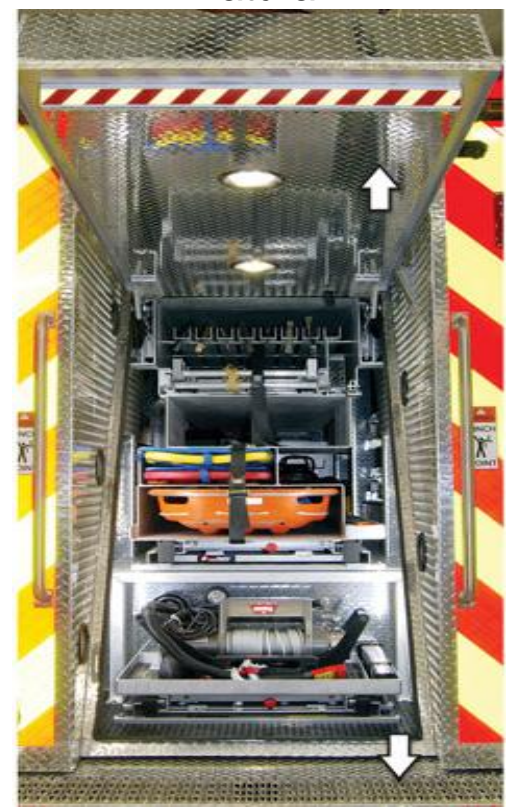

Fonte: Adaptado de FireAssaratus. Retirado em 12 de dezembro de 2020.

Site:https://www.fireapparatusmagazine.com/2017/06/13/dollars-and-sense-rescue-truck-options/\#gref.

\subsubsection{Substituição do EMVS tipo cesto}

O TA buscou sugeriu a substituição do EMVS tipo cesto pelo que há de melhor no mercado. Optou-se a um EMVS tipo cesto com um de material de maior durabilidade e resistência, sendo de aço inox ou titânio, em substituição ao EMVS cesto atual do CBPMESP.

A troca é devido a certificação UL NFPA 1983-2012 e CE, além de ser referência quanto a sua utilização por equipes das Forças Armadas dos EUA (TITAN, 2012) e pela equipe Groupe de Reconnaissance et d'Interventionen Milieu Périlleux (GRIMP) que, em português significa, grupo de reconhecimento e intervenção de ambientes perigosos.

O equipamento tipo inox tem formato regular, construído com uma estrutura totalmente inoxidável, soldado com solda TIG e projetado para além do limite de $1.134 \mathrm{~kg}$ de carga estática. Apesar de robusto, seu peso é relativamente igual ao tipo convencional de $13 \mathrm{~kg}$. Já o EMVS de titânio possui 
as mesmas características, porém seu peso é de 6 kg(TRAVERSE RESCUE,2012).

Quanto as vantagens do equipamento, a primeira é não ter a degradação do material de forma rápida, durante a ação do tempo. Além de ser resistente à luz solar e intempéries. O equipamento pode ser utilizado tanto na vertical como na horizontal, tendo capacidade de ruptura respectivamente de 30 KN e 14 KN (TRAVERSE RESCUE, 2012).

Uma segundaé quanto ao seu acondicionamento. Por ter a opção de ser desmontável, ocupa menor espaço para acomodação. Isso facilita equipes de resgate com helicópteros e de equipes aéreas. A Figura 5 ilustra um modelo de EMVS tipo cesto de aço inox da marca Ferno Rescue®. Como pode ser observado, há um sistema de encaixe rápido que facilita a montagem do equipamento em até 15 segundos, conforme o manual do fabricante.

Figura 5- Maca cesto de titânio desmontável

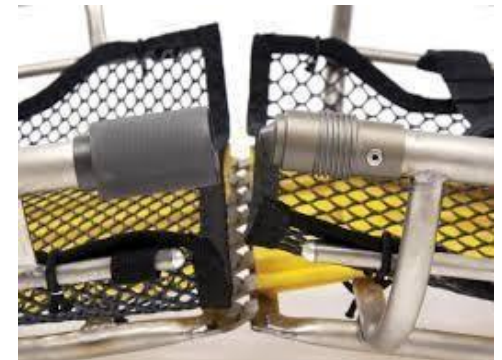

Fonte: Adaptado de FernoRescue $\AA$. Retirado em 18 de dezembro de 2020.

Site: http://www.fernorescue.com/products/basic-rescue/basket-stretchers

E a terceira vantagem é a utilização de mosquetões de qualquer tamanho em pontos específicos do equipamento EMVS tipo cesto. Por ficar presos nos pontos de conexão StratLoad®,os mosquetões podem ser adaptados a estes pontos, ao contrário dos EMVS tipo cesto utilizados hoje no CBPMESP. A Figura 6 ilustra a base estrutural composta com quatro pontos de conexão visíveis que tornam mais rápido, fácil e seguro prender os tirantes durante o trabalho vertical. 
Figura 6 - EMVS tipo cesto titânio com içamento na horizontal

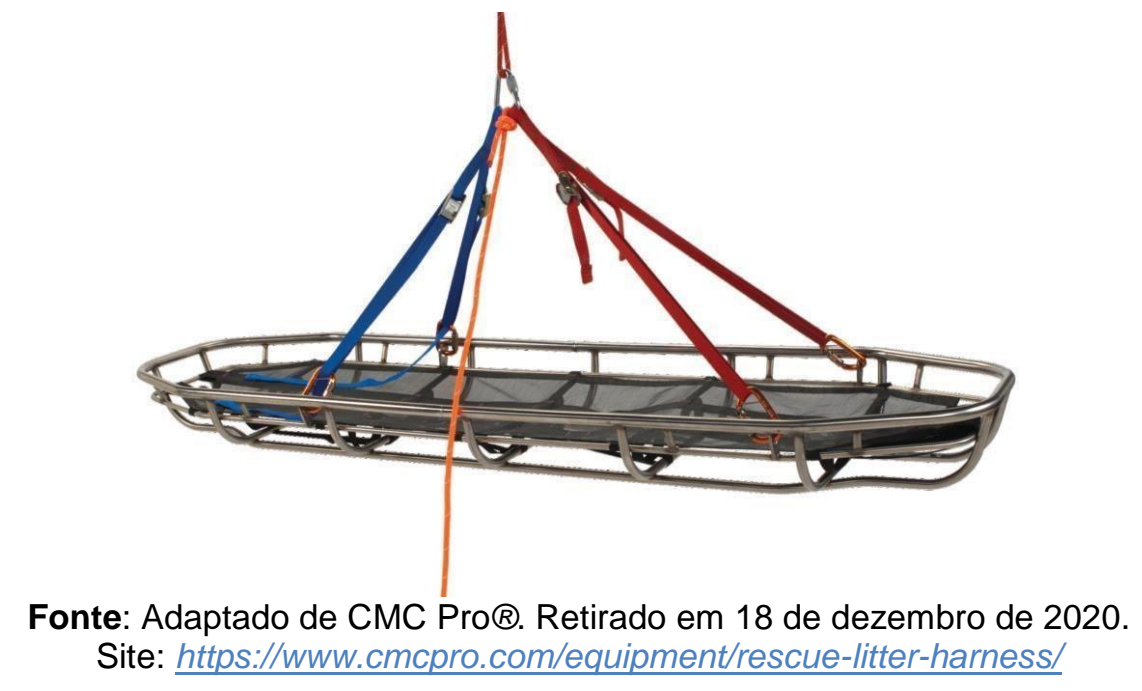

A última vantagem é que os EMVS tipo cesto Inox é mais fácil para a manutenção. Ela é facilitada por sua simplicidade na hora da limpeza que é básica, com produtos como agua e sabão neutro.

A higienização do equipamento não afeta sua resistência no uso diário devido ao material ter estrutura simples, composta de tubos de aço inox ou titânio. E, em casos de descarte, o material pode ser reaproveitado, uma vez que esse tipo de material e sua estrutura torna-se um atrativo no mercado de materiais recicláveis, maior que a do material plástico.

\subsubsection{Ancoragem padronizada de cabeceira no CBPMESP}

Em relação a ancoragem de cabeceira, foi visto que os departamentos da ESB apresentam diferenças quanto à técnica, conforme observado na Figura 2. E, ao observar a literatura institucional, não há referências que demonstre a forma padronizada de se realizar essa amarração por parte do CBPMESP.

Porém, a fabricante Spencer® alega que o equipamento atual utilizado pelo CBPMESP, para o içamento vertical deve: 
"ser mantida horizontalmente para o chão, quaisquer inclinações anormais podem causar sérios danos ao paciente, o dispositivo e 0 operador". E ainda que para içar usar "apenas os pontos de fixação adequados para ganchos, e além do mais é para evitar o arraste da maca sobre pedras, ramos ou superfícies perigosas que possam afetar a integridade do dispositivo"(SPNECER, 2016)".

Apesar desta característica, há outros fabricantes que recomendam o uso na posição vertical. Porém, alertam que a inclinação deve seguir orientações contidas no manual, com uso de cordas ou mosquetões nos pontos de fixação e que a utilização de uma estrutura rígida externa, na forma correta dos ângulos, deve ser executada por pessoas capacitadaspara a tarefa (FERNO, 2012).

Portanto, para sugestão de padronização no CBPMESP, observando os atuais EMVS tipo cesto que ainda se encontram em operação, sugere-se a amarração de cabeceira com uso dos ilhoes. A padronização da amarração evita riscos desnecessários e facilita as estações de Bombeiros no tocante a formulações de procedimentos operacionais, itens imprescindíveis detectados e caracterizados no OAC nas atividades de Bombeiros.

A Figura 7 ilustra as sugestões do TA conforme orientações dos fabricantes Spencer (2016), que é o EMVS tipo cesto mais utilizado no âmbito da CBPMESP.

Para o içamento na posição vertical, O TA propôs as opções:

1- Amarração com a utilização da própria corda de tração, utilizando-se do nó 7 (sete) follow me, conforme Fotografia à direita.

2- Amarração com a utilização de 2 (duas) fitas de mesmo tamanho e 2 (dois) mosquetões, ambos ancorados na corda de tração, conforme Fotografia do meio.

3- Amarração com a utilização de 1 (uma) fita envolvendo os dois "ilhós" de mesmo tamanho e 1 (um) mosquetão, ancorados na corda de tração, Fotografia da esquerda.

4- Para o EMVS de inox ou titânio manteria a mesma técnica, porém utilizando pontos de conexão StratLoad®. 
Revista Científica do Corpo de Bombeiros Militar de Pernambuco

Artigo Publicado no Vol.07 N.20 - Edição Especial 2021 - ISSN 2359-4829

Versão on-line disponível em: http://www.revistaflammae.com

Figura 7 - Tipo de amarração de cabeceira em EMVS tipo cesto da marca Spencer®.
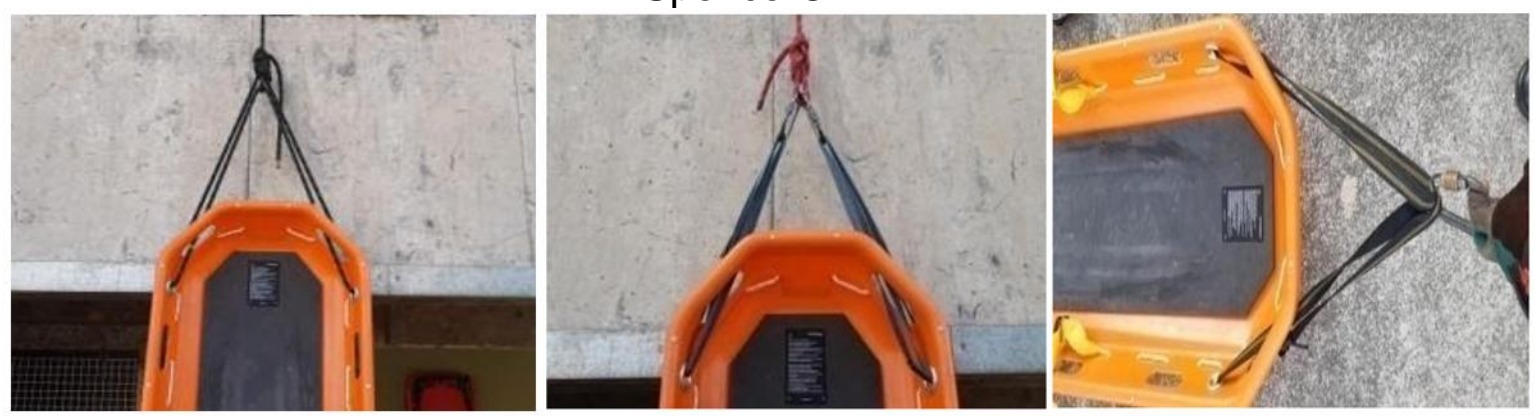

Fonte: Elaborado pelo autor.

\subsection{Fase 3 - Comprovação Prática}

\subsubsection{Estudo de implementação e investimento}

Para a implementação, observou-se que o EMVS tipo cesto inox foi avaliado em todos os "gaps de uso", sendo analisado em operações de salvamento, treinamento e simulação prática de resgate em local de difícil acesso. Locais como espaço confinado, local de difícil acesso como barrancos e precipícios foram analisados conforme a normalidade do estudo.

Para a etapa de investimento, o CBPMESP realizada a aquisição dentro das aquisições de materiais e serviços realizadas pelas Unidades Gestoras Executoras (UGE). A aquisição é feita por processo licitatório e segue as diretrizes da Lei Federal o 8.666, de 12 de dezembro de 1968, com a clara exemplificação dos princípios da gestãopúblicabrasileira, dentro dos princípios constitucionais legais.

Na oportunidade, a UGE 180.199 - Administração do Corpo de Bombeiros da ESB, realiza a compra de maneira centralizada e, assim, pode ser comprado e distribuído para todo o Estado.

\subsubsection{Aplicação prática}

Dentro do que analisou o TA,o EMVS tipo cesto de aço inox ou titânio baseou-se nas seguintes observações práticas: 
1. Quesito peso do equipamento - A de aço inox equipara-se ao peso do EMVS atual de corpo plástico, porém a marca tipo titânio tem peso de $6 \mathrm{~kg}$.

2. Quesito adaptabilidade - É de fácil manuseio, pode ser desmontável e adaptável para o compartimento da viatura, além de possuir pontos de conexão StratLoad® que facilita o uso de qualquer tipo de mosquetão.

3. Quesito degradação - A degradação do equipamento é menor. $\mathrm{Na}$ ocasião, não se soma a degradação dos acessórios, uma vez que estes podem ser removíveis do EMVS tipo cesto.

4. Quesito estrutura- A estrutura do EMVS tipo cesto inox ou titânio permite ao equipamento ficar exposto ao tempo, caso não tenha espaço específico nas viaturas, tal como ocorre atualmente nas viaturas do CBPMESP.

5. Quesito carga- OEMVS tipo cesto Inox poder trabalhar com carga além do previsto, apresentando vantagem superior ao EMVS tipo cesto com corpo plástico. A proporção é de cerca de 4,05 vezes, sendo o equipamento tradicional suportar até $280 \mathrm{Kg}$ de carga total e o tipo aço inox/titânio suportar até $1.134 \mathrm{~kg}$.

Além das observações práticas foram destacadas observações teóricas que trouxeram o diferencial quanto a implementação do equipamento no âmbito do CBPMESP. As observações teóricas quanto a metodização foram:

6. Certificação NationalFireProtectionAssociationNFPA - Está norma subsidia e fornece credibilidade ao equipamento, como preconizado pela NFPA 1500 e NFPA 1407. As certificações são comumente utilizadas por equipes de intervenção rápida de Bombeiros norte americano e Forças Armadas Americana;

7. Orientações de uso e procedimento - Grande parte do EMVS tipo cesto inox ou titânio contempla a forma de utilização e a capacidade 
de tração, enquanto os modelos de EMVS tipo cesto usual acabam por não contemplar;

8. Resgate em águas - O EMVS tipo cesto inox ou titânio facilita o escoamento da água por ser totalmente vazado, ao contrário do tipo cesto usual;

9. Limpeza do equipamento - Por ter apenas estruturas de aço o EMVS tipo cesto inox possibilita a facilidade na hora da limpeza, além do material evitar a corrosão, por se tratar de um aço melhor trabalhado;

10. Uso de acessórios diversos - O uso de acessórios entregues pelo fabricante, como no caso para a adaptação para ambientes de represas e lagoas. Na Figura 7, por exemplo, há a ilustração de um modelo EMVS tipo cesto inox com o acessório de colar de flutuação, utilizado para manter a vítima,que está em seu interior, na superfície d'água.

Figura 7-EMVS tipo cesto inoxcom acessório de flutuação para uso em águas

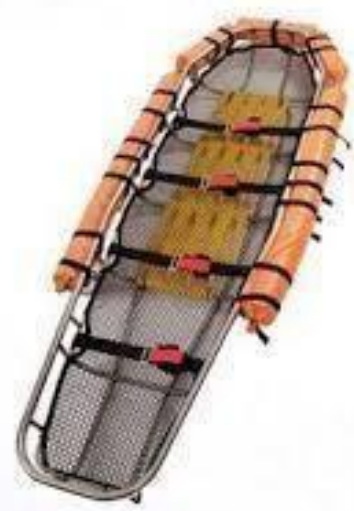

Fonte: Adaptado de Risk Responde. Retirado em 18 de dezembro de 2020.

Site: https://riskresponse.edu.au/collections/marine/products/471-floatation-collar-for-stretchers.

Além das observações práticas e teóricas citadas há de se destacar fatores que melhoram ou potencializam a durabilidade do material e oferecem 
qualidade no atendimento à vítima, contidas nos referidos manuais dos equipamentos.

Em outras ocasiões de salvamento que inclui o arrasto de vítimas em superfícies porosas em cachoeiras, por exemplo, sugere-se a aplicação do EMVS tipo envelope. Tecnicamente, este equipamento é melhor utilizado para outras facilidades operacionais nos serviços de Bombeiros.

Na oportunidade do CBPMESP adotar um POP, o passo a passo, de um processo de criação, é lento e burocrático. Apesar de facilitara linguagem universal entre os colaboradores Bombeiros, O POP mitigaria possíveis erros operacionais no quesito içamento vertical com amarração de cabeceira. Como ocorreu no estudo de caso apresentado.

Outra oportunidade, é que se criar umRescuelntervention Team (RIT),em português, time de intervenção rápida, para a necessite de resgate de Bombeiros feridos ou de vítimas em locais sinistrados com chamas, as equipes estariam utilizando equipamento que atendesse as especificações internacionais nos moldes das equipes internacionais de RIT no mundo.

\section{CONCLUSÃO}

Neste artigo, a proposta procurou enfatizar o processo de aquisição e utilização de um equipamento EMVS tipo cesto que atendesse a todos os requisitos operacionais utilizados durante um salvamento de Bombeiros. Propôs-se a troca utilizando uma abordagem metodológica diferenciada, cuja metodologia empregada exemplificasse, etapas do processo administrativo da administração pública, com a clara exemplificação dos princípios constitucionais legais, até a prática aplicação do equipamento em âmbito operacional.

Observou-se frente aos resultados que a troca do equipamento EMVS tipo cesto titânio ou inox é mais eficaz para as atividades de Bombeiros e a 
padronização da amarração de cabeceira por meio de um POP, em todo 0 contexto de salvamento na organização, deve ser aspecto àser analisados por todas as organizações dos Corpos de Bombeiros, a fim de melhorar 0 atendimento operacional ofertado por estas instituições.

Como limitação, ocorreu a análise apenas no âmbito do Corpo de Bombeiros do Estado de São Paulo, além de ter sido lento e burocrático todo a sistemática do processo. Sugere-se, para pesquisas futuras, avaliar outras instituições de resgate e emergências médicas como os times de resgate das Forças Armadas Brasileiras, organizações de Bombeiros do Brasil e organizações privadas, que efetuam resgates emergenciais de locais de difícil acesso, o uso do equipamento e o retorno por parte dessas instituições de salvamento e resgate.

\section{AGRADECIMENTOS}

Este trabalho foi realizado observando o conjunto de experiências dos autores nos exercícios da atividade de Bombeiros. Na literatura há trabalhos que descrevem particularidades específicas, no entanto, julgou-se mais adequado citar novas fontes que serviram de consulta para o conhecimento no assunto. Diante dos fatos, agradecemos à ESB pelo apoio e disponibilidade de meios e materiais, como aos docentes Bombeiros que elucubraram, com suas expertises, para melhor aprimoramento deste trabalho.

\section{REFERÊNCIAS}

ASSOCIAÇÃO BRASILEIRA DE NORMA TÉCNICAS - ABNT. Projeto de revisão NBR 13230: Simbologia Indicativa de reciclabilidade e identificação de materiais plásticos. Rio de Janeiro, 8p. (2006).

BORBA, C. H. S.; SANTOS, Z. I. G.; SANTOS, R. F. A.; REIS, M. M. Estudo do efeito da radiação UV em compostos de polietileno. In: $22^{\circ} \mathrm{CBECiMat} \mathrm{-}$ 
Congresso Brasileiro de Engenharia e Ciência dos Materiais, 2016. Natal/RN. Anais [...]Universidade Federal de Sergipe - UFS, 2016 p.8927-8937.

Disponível em: <http://www.metallum.com.br/22cbecimat/anais/PDF/406032.pdf> Acesso em: 23 mar 2020.

CARASCHI, José Cláudio; LEÃO, Alcides Lopes. Avaliação das propriedades mecânicas dos plásticos reciclados provenientes de resíduos sólidos urbanos. Acta Scientiarum Technology, v. 24, p. 1599-1602, 2002.

$\mathrm{CHO}$, Byung-Jun et al. The StudyofupperbodyangleofFire-Fighters carrying a Patienton a StretcherwithHelmets. Research Journal of Pharmacyand Technology, v. 11, n. 1, p. 363-368, 2018.

COLTRO,Leda; GASPARINO, Bruno F.; QUEIROZ,Guilherme de C. Plastic materials recycling: the importance of the correct identification. Polímeros, vol.18, n.2, São Carlos, Apr./June, 2008.

CROME, L. The Stretcher Problem. British medical journal, v. 2, n. 4111, p. 819, 1939.

DA SILVA, Clemar Corrêa. Assessoria médica e de resgate em expedições e esportes em áreas remotas. Revista de Medicina, v. 91, n. 1, p. 19-24, 2012.

IWANO, Yuki; OSUKA, Koichi; AMANO, Hisanori. Developmentofrescuesupportstretcher system withstair-climbing. In: 2011 IEEE - International Symposiumon Safety, Security, and Rescue Robotics. p. 245-250, 2011.

KITANO, Hiroaki et al. Robocuprescue: Search andrescue in largescaledisasters as a domain for autonomousagentsresearch. In: IEEE SMC'99 Conference Proceedings. 1999 IEEE InternationalConferenceon Systems, Man, and Cybernetics. p. 739-743, 1999.

LAWRENCE, Ernert O. Rescue Basket. Lawrence Radiation laboratory. University of California. Contract, $\mathrm{n}^{\circ} \mathrm{W}-7405$, eng. 48, Livemor California, 1964.

OKADA, Alexandra Lilavati Pereira. Desafio para EAD: Como fazer emergir a colaboração e cooperação em ambientes virtuais de aprendizagem? Capítulo do Livro: SILVA Marco. Educação Online. São Paulo, Loyola, 2003.

PASQUIER, M. et al. Helicopter rescue operations involving winch in go fan emergency physician. Injury, v. 43, n. 9, p. 1377-1380, 2012. 
PMESP, POLÍCIA MILITAR DO ESTADO DE SÃO PAULO. Coletânea de Manuais técnicos de Bombeiros. Manual 03 - Salvamento Terrestre. $2^{\mathrm{a}}$ edição, Estado de São Paulo, p.125, 2006a.

. Coletânea de Manuais técnicos de Bombeiros. Manual 26 PMESP, Salvamento em Altura, $1^{\underline{a}}$ edição, Estado de São Paulo, p. 136, 2006b.

Estado de São Paulo, 2019.

Manual de Fundamentos do Corpo de Bombeiros. $2^{\mathrm{a}}$ edição,

SANTOS SOUZA, Antonio Carlos dos. Objetos de Aprendizagem Colaborativos. Artigo submetido a Associação Brasileira de Educação a Distância - ABED. In: Congresso 2055. Centro Federal de Educação Tecnológica da Bahia. Data de envio: 05/2005.

SHELL - TWIN SHELL - SPENCER _ MANUAL DE UTILIZADOR, Manual do fabricante Spencer, First edition: 07 out 2013. Rev. 5: 21 nov 2016. Disponível em: https://www.spencer.it/ media/586/downloads/user manual/shell twin shell rev5 en.pdf. Acesso em : 12 abr 2020.

SKEDCCO. Inc. Corporations. Instructions and saving lives. The Complete rescue system. Available: https://skedco.com/wpcontent/uploads/2020/02/NEW-SKED-INSTRUCTION-Standard-Size.pdf Acesso: 03 Abr 2020.

SPENCER. User's Manual of Basket strechers Twin Shell and Spencer Shell. First edition: Oct, 13. Rev. 5. Nov 2016. Disponível em: https://www.spencer.it/media/586/ downloads/user manual/shell twin shell rev5 en.pdf. Acesso em: 03 abr 2020.

STRICKLAND, Capitão J. Divisão de Operações Especiais de Resgate de Incêndios em Miami-Dade, 2000. Disponível em: https://forums.firehouse.com/forum/rescue-pecial-ops/specializedrescue/5892-stokes-baskets. Acesso em: 12 abr 2020.

FERNO. TRAVERSE RESCUE modelo TITAN, manual do usuário, 2012. Disponível em :http://www.fernorescue.com/products/basic-rescue/basketstretchers/traverse-titan-ti-split-basket-stretcher-titanium. Acesso em: 12 abr 2020.

VARGHESE, Tommy. Innovation: The simple stretchers. Medical Journal, Armed Forces India, v. 59, n. 1, p. 42, 2003. 